\title{
Energy expenditure of flight crew of military transport aviation depending on function during typical training activities
}

\author{
Bartosz Bertrandt ${ }^{1}$, Roman Lakomy ${ }^{2}$, Pawel Kler ${ }^{3}$ and Jerzy Bertrandt ${ }^{2}$ \\ ${ }^{1}$ KADAR Co., Lesznowola, Poland, \\ ${ }^{2}$ Laboratory of Food and Nutrition Hygiene, Military Institute of Hygiene and Epidemiology, Warsaw, Poland and \\ ${ }^{3}$ Military University of Technology, Warsaw, Poland
}

\section{Abstract}

Introduction: The knowledge of energy expenditure during typical activities is the basic information to estimate nutritional requirements. This is especially important with irregular lifestyle, such as service in transport aviation. Aircraft personnel fly in every part of a day. Flights often take place with changes in climate and time zones. Time of flights fluctuated from a several dozen to a dozen hours.

Aim: The aim of the work was to assess and compare the energy expenditure of military aircraft crews - "CASA C-295", "C-130 Hercules" and helicopter "W-3 Sokol" during typical air training activities.

Material \& Method: The study was conducted in a group of 31 members of flight crews. The energy expenditure was based on the examination of heart rate frequency with the Polar RS800 heart rate monitor.

Results: The study was conducted among crew members of various types of transports aircrafts. The average value of energy expenditure of the CASA pilots $(\mathrm{n}=14$ ) was $3,071 \pm 0,84 \mathrm{kcal} / \mathrm{min}$ (training flight during the day, $\mathrm{n}=10$ ) and $5,64 \pm 2,45 \mathrm{kcal} / \mathrm{min}$ (training flight during the night and in noctovision goggles, $n=4)$. In a group of flight technicians $(n=7)$ in aircraft Herules $C$ - 130 the average energy expenditure was $3,55 \pm 1,83 \mathrm{kcal} / \mathrm{min}$ (passeneger reception and service). In a group of loadmasters $(\mathrm{n}=6)$, in aircraft CASA and Hercules C-130 the average energy expenditure was 6,63 $\pm 1,55 \mathrm{kcal} / \mathrm{min}$ (baggage service, dropping paratroopers). The average energy expenditure in a group of paramedics $(n=4)$, which are members of helicopter $\mathrm{W}-3$ Sokol crew was $8,51 \pm 4,29 \mathrm{kcal} / \mathrm{min}$ (going down the rope, lifting wounded person from watercrafts).

Conclusion: The presented data show the variation in energy expenditure between groups, as well as within groups. The energy expenditure was varied depending on the function on board and on the conditions in which the tasks were performer. Obtained values of energy expenditures during flights allow to classify the work performed in the categories of work from light to heavy (according to the Christensen's classification). Nutrition in the study group should be adapted to the nature of the work performed.

\section{Conflict of Interest}

There is no conflict of interest. 